\title{
Placenta and Transvaginal Sonography
}

\author{
Ashok Khurana
}

\begin{abstract}
In recent years, transvaginal evaluation of the placenta has completely changed the way obstetricians need to perceive and assess a low-lying placenta. Additionally, the number of negative ultrasound examinations in morbid placental adherence has reduced. This article presents the evidence on the safety and accuracy of transvaginal placental evaluation and goes on to discuss the manner in which transvaginal findings should alter clinical protocols to optimize maternal and fetal outcomes. It also answers a very pertinent clinical question: How low is low?
\end{abstract}

Keywords: Low-lying placenta, Magnetic resonance imaging, Safety and accuracy of transvaginal sonography.

How to cite this article: Khurana A. Placenta and Transvaginal Sonography. Donald School J Ultrasound Obstet Gynecol 2018;12(2):137-144.

Source of support: Nil

Conflict of interest: None

\section{SAFETY AND ACCURACY OF TRANSVAGINAL ULTRASOUND}

Transabdominal scans are associated with a falsepositive rate of diagnosing placenta previa in about $25 \%$ of cases. ${ }^{1,2}$ This is consequent to multiple factors including a posterior location, ${ }^{3}$ shadowing from the fetal head, ${ }^{4}$ maternal abdominal obesity, ${ }^{5}$ and underfilling or overfilling of the fetal urinary bladder. ${ }^{6,7}$ Transvaginal scanning is now an unarguably accurate method for localizing a low placenta. ${ }^{8-11}$ As many as $60 \%$ of patients will have a reclassification of placental position on a transvaginal evaluation $^{1}$ and a representative study reports a sensitivity of $87.5 \%$, a phenomenal specificity of $98.85 \%$, a positive predictive value of $93.3 \%$, and a negative predictive value of $97.6 \%{ }^{12}$ A randomized control study ${ }^{13}$ has also confirmed the accuracy of transvaginal studies. In fact, transvaginal scanning has greatly reduced the incidence of placenta previa $^{9,14}$ because of its better delineation of the internal os and inferior placental margin; three-dimensional (3D) transvaginal evaluation of the placenta and cervix holds great promise as shown in recent preliminary studies. ${ }^{15}$

\section{Consultant}

Department of Reproductive Ultrasound, The Ultrasound Lab Defence Colony, New Delhi, India

Corresponding Author: Ashok Khurana, Consultant Department of Reproductive Ultrasound, The Ultrasound Lab Defence Colony, New Delhi, India, e-mail: ashokkhurana@ ashokkhurana.com
The safety of transvaginal scanning is also not in doubt $^{3,10,16}$ and the technique, in spite of initial skepticism, now has widespread acceptance. ${ }^{1}$

As a consequence, the clinical presentation of placenta previa has changed and most low-lying placentas are diagnosed during the second trimester anomalies scan.

\section{MAGNETIC RESONANCE IMAGING EVALUATION}

The diagnostic accuracy of magnetic resonance imaging (MRI) and ultrasonography for placenta accreta is comparable. ${ }^{16}$ The MRI serves as an adjunctive modality if there are ambiguous ultrasound findings or a suspicion of a posterior placenta accreta.

Controversy surrounds the use of gadolinium-based contrast enhancement, even though it increases the specificity of a diagnosis of placenta accreta. Gadolinium crosses the placenta and readily enters the fetal circulatory system. The Contrast Media Safety Committee of the European Society of Urogenital Radiology reviewed the literature and determined that no effect on the fetus has been reported following the use of gadolinium contrast media. ${ }^{17}$ The American College of Radiology guidance document for safe MRI practices recommends that intravenous gadolinium should be avoided during pregnancy and should be used only if absolutely essential. ${ }^{18}$

\section{PLACENTA PREVIA}

The confusion that existed in the "classification" and nomenclature of placental location has undergone significant clarification over the past decade, and a clinically relevant understanding of placental location is now apparent. Terms, such as "low-lying placenta," "marginal placenta previa," "partial placenta previa," and "total placenta previa" all refer to an abnormally low placenta. A total placenta previa completely spans across the internal os (Fig. 1). A partial placenta previa partially spans across the internal os (Fig. 2). A marginal placenta extends down to the internal os, but does not span across it (Fig. 3). It is appropriate to specify the distance between the lower margin of the placenta and the internal os. ${ }^{1}$ A placenta that extends down to the internal os is $0 \mathrm{~mm}$ away from the internal os. The amount of placenta that overlaps the internal os should also be measured and the distance reported in $\mathrm{mm} .^{1}$

It is also now clear that changes in placental location occur throughout gestation and are consequent to two phenomena, formation of the lower uterine segment and 


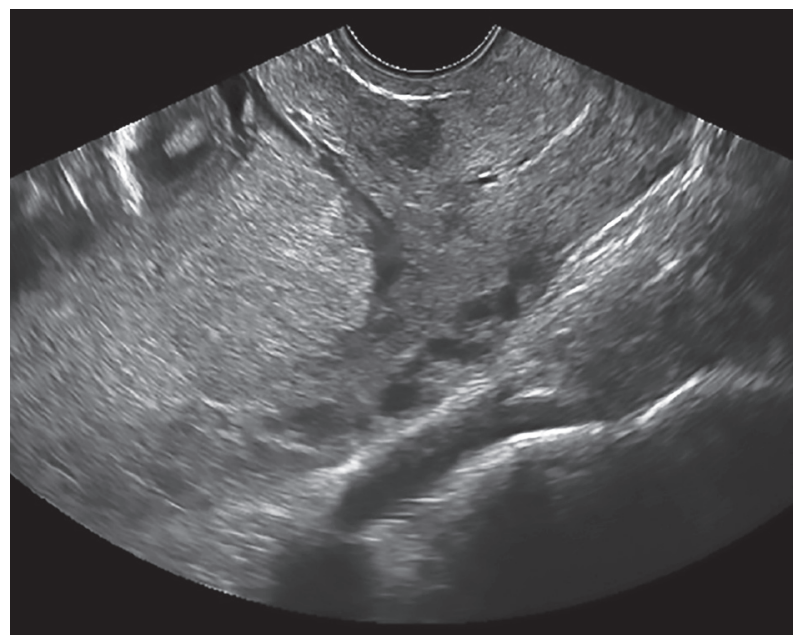

Fig. 1: Complete placenta previa. Transvaginal image shows a posterior wall placenta spanning across the internal os and extending onto the anterior uterine wall. The ++ calipers measure the extent of the placenta beyond the internal os. This measurement is clinically relevant because the greater the extent beyond the os the smaller the chance of "resolution" of a placenta previa
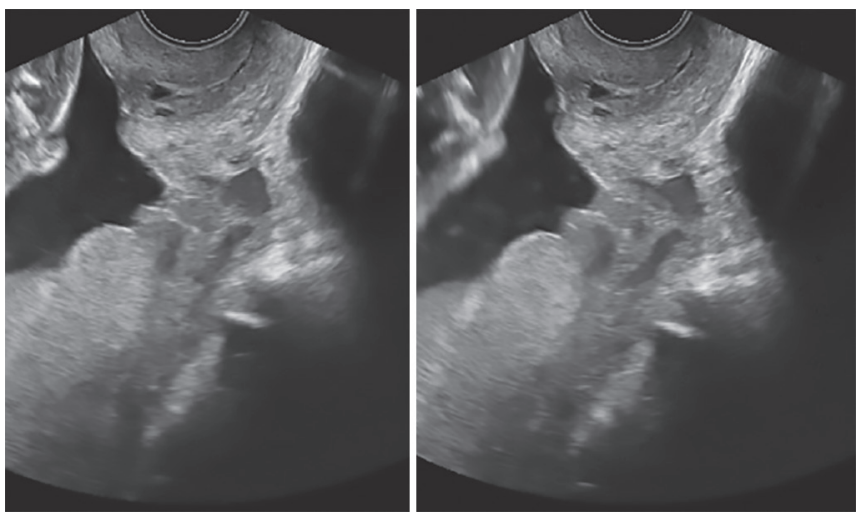

Fig. 3: Marginal placenta previa. This low-lying placenta extends down to the internal os but does not span across it

placental trophotropism. ${ }^{11,19,20 ~ " T r o p h o t r o p i s m " ~ i s ~ t h e ~}$ term used to describe preferential proliferation of trophoblastic villi in regions of better endometrial supply along with atrophy of villi in areas with a poorer blood supply. ${ }^{19,20}$ Placental position and shape can therefore, change as pregnancy progresses. Trophotropism explains resolution of placenta previa, increase in pathologic extent of placenta previa, the development of succenturiate lobes or a bilobed placenta, odd-shaped placentas and abnormal cord insertions. Over $90 \%$ of placentas that are low lying at 20 weeks of gestation will achieve a normal position at term. ${ }^{11,21} \mathrm{~A}$ low placenta is evident in about two-fifths of patients at 11 to 14 weeks, in about 1 in 25 patients at 20 to 24 weeks, and about 1 in 50 patients at term. ${ }^{22}$ Predisposing factors for placenta previa include previous cesarean section, previous cavitary surgery, previous vigorous curettage, multiparity, and advanced maternal age. $19,23,24$
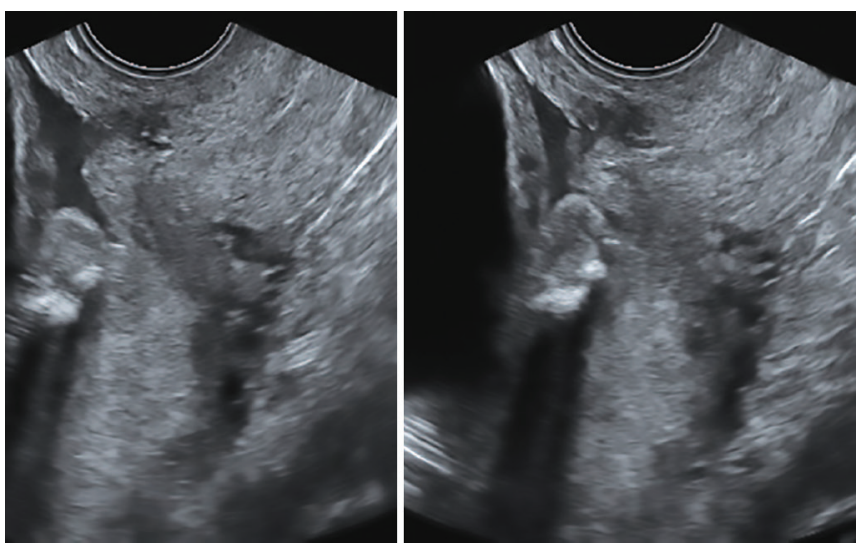

Fig. 2: Partial placenta previa. The lower limit of this low-lying placenta extends down to the internal os, partially spans across it, but does not extend beyond the os

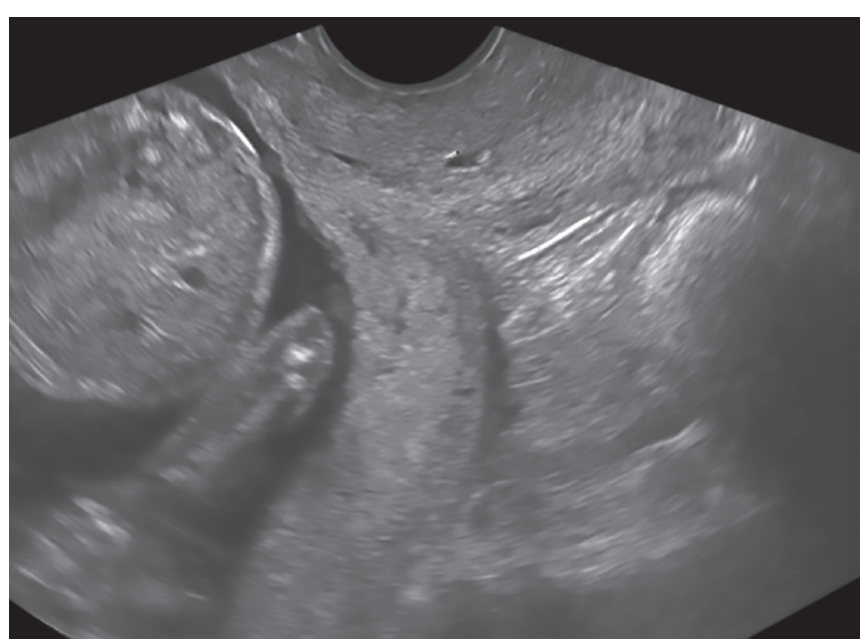

Fig. 4: Marginal placenta previa with a thin beak like lower edge. The morphology of the inferior edge has a bearing on clinical outcome. Placentas with a rounded lower edge (Fig. 5) are more likely to resolve at term unlike this one, which is likely to persist till term. The cervix should be measured in all low placentas. The chances of bleeding are higher with a short cervix

Serial evaluation demonstrates placental migration ${ }^{25}$ and it is possible to predict which cases will persist to term. ${ }^{7,9,14,22,26-28}$ A review of these studies indicates that placentas that overlap the cervix by a distance greater than 10 to $15 \mathrm{~mm}$ in the second trimester are likely to be persistently low at term. Most placentas that do not overlap the internal os are likely to "resolve" at term. Vaginal delivery is generally possible once the placenta is $20 \mathrm{~mm}$ superior to the internal os. A significant number of pregnancies with placentas between 10 and $20 \mathrm{~mm}$ can also be delivered vaginally. Another ultrasound feature that also influences placental migration is the morphology of the inferior edge of the placenta. ${ }^{29}$ Placentas with a thin inferior edge (Fig. 4) are more likely to persist in a low position compared with those with a thick lower edge (Fig. 5).

The risk of bleeding from a placenta previa depends on several factors. Irrespective of the distance of a low 


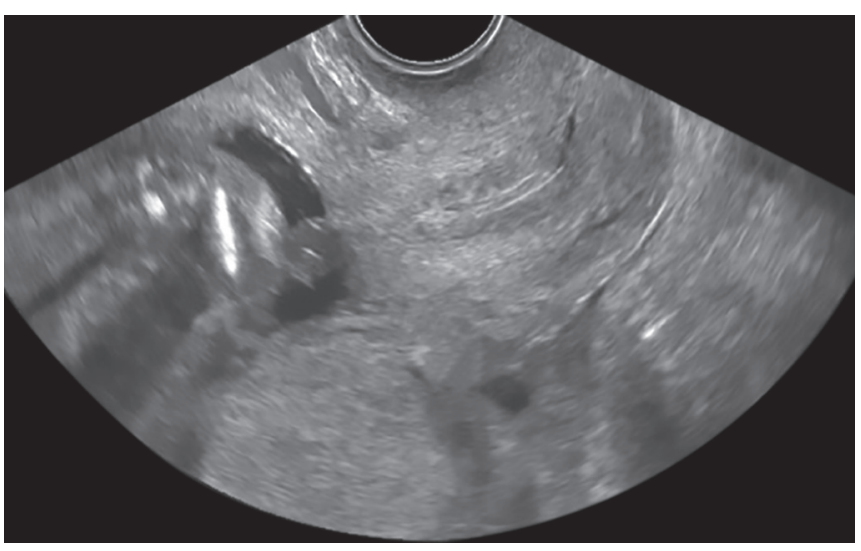

Fig. 5: Low placenta with a round lower edge. This type is more likely to migrate away from the internal os as pregnancy progresses to term

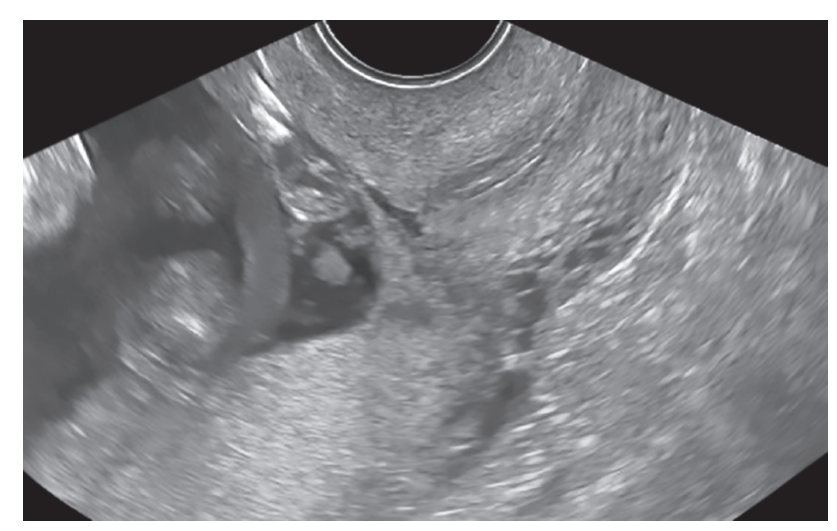

Fig. 7: Note the echo free fluid space between the placenta and the internal os. Low placentas with such a morphology are more likely to bleed

placenta from the internal os, most patients who do have antepartum bleeding, will not have episodes which are life-threatening or require premature delivery. ${ }^{1}$ It must be emphasized, however, that pregnancies with a placenta that is within $40 \mathrm{~mm}$ of the internal os do have a higher risk of postpartum hemorrhage. ${ }^{1}$ The distance of a low-lying placenta from the internal os does not seem to influence the risk of antepartum bleeding. This is more influenced by cervical length ${ }^{30-32}$ and the presence of an echo-free space (Fig. 6) in the lower edge of the placenta overlying the internal os ${ }^{33}$ (Fig. 7). Both these factors increase the possibility of the need for an emergency delivery prior to 34 weeks of gestation. Most patients without these two features can be managed expectantly without hospitalization. ${ }^{34-37}$ Cervical cerclage for a short cervix with a low placenta is not justified. ${ }^{1,37,38}$ Placenta accreta and vasa previa are intimately associated with placenta previa. ${ }^{39-41}$ In this situation, timed operative delivery $^{42,43}$ in an appropriate setting greatly improves perinatal outcomes. Evidence of placenta previa should, therefore, prompt a careful ultrasound evaluation for placenta accreta and vasa previa. ${ }^{1,40}$

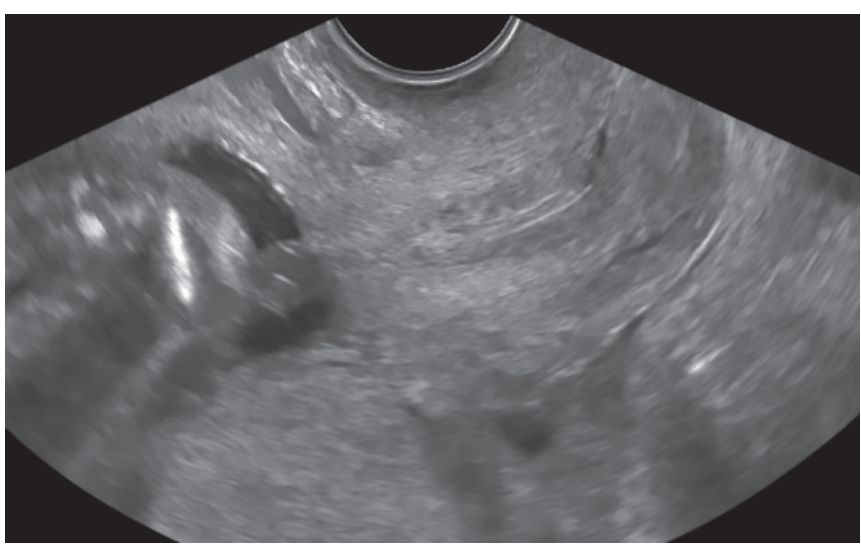

Fig. 6: Note the echo free fluid space between the placenta and the internal os. Low placentas with such a morphology are more likely to bleed
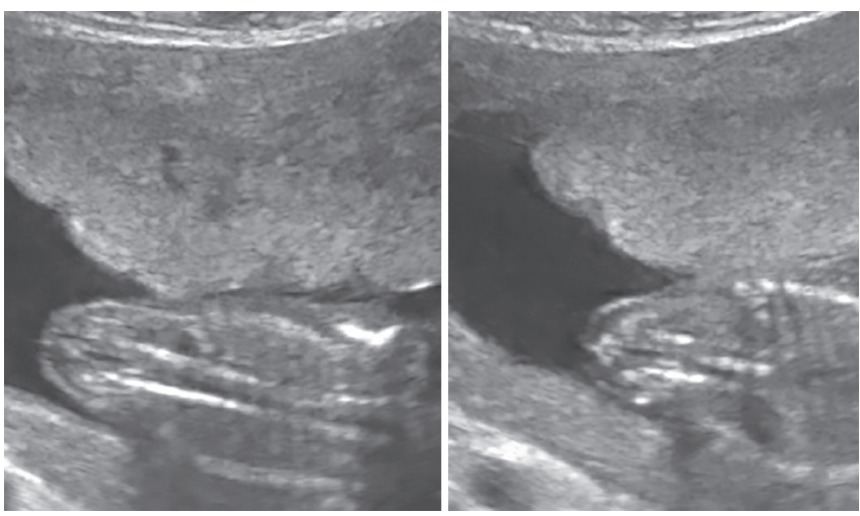

Fig. 8: Placenta accreta. Note the extensively obscured interface that should have been seen as a hypoechoic zone between the basal extent of the placenta and the subplacental myometrium

\section{PLACENTA ACCRETA}

The term "placenta accreta" is the generic term for abnormal adherence of the placenta to the uterus. It is consequential to a defect in the fibrinoid (Nitabuch's) layer of the decidua ${ }^{44}$ underlying the placenta. The term "placenta accreta vera" is used when the placenta is adherent to the myometrium, but does not invade it (Fig. 8). When myometrial invasion takes place, the term "placenta increta" is used (Fig. 9). Placenta percreta refers to the situation where invasion extends beyond the uterine serosa and into the urinary bladder (Fig. 10) or rectum. The placenta does not separate after delivery and can result in a situation of retained placenta, life-threatening hemorrhage or uterine rupture, not infrequently requiring an emergency hysterectomy. Risk factors include previous cesarean section, previous curettage, previous morbid adherence, a low-lying placenta, advanced maternal age, submucous fibroids and anomalies of uterine structure, such as uterine horns. ${ }^{4-47}$ Accurate prenatal identification of affected pregnancies allows optimal management because timing and site of delivery, availability of blood products, and recruitment of a skilled anesthesia and surgical team 


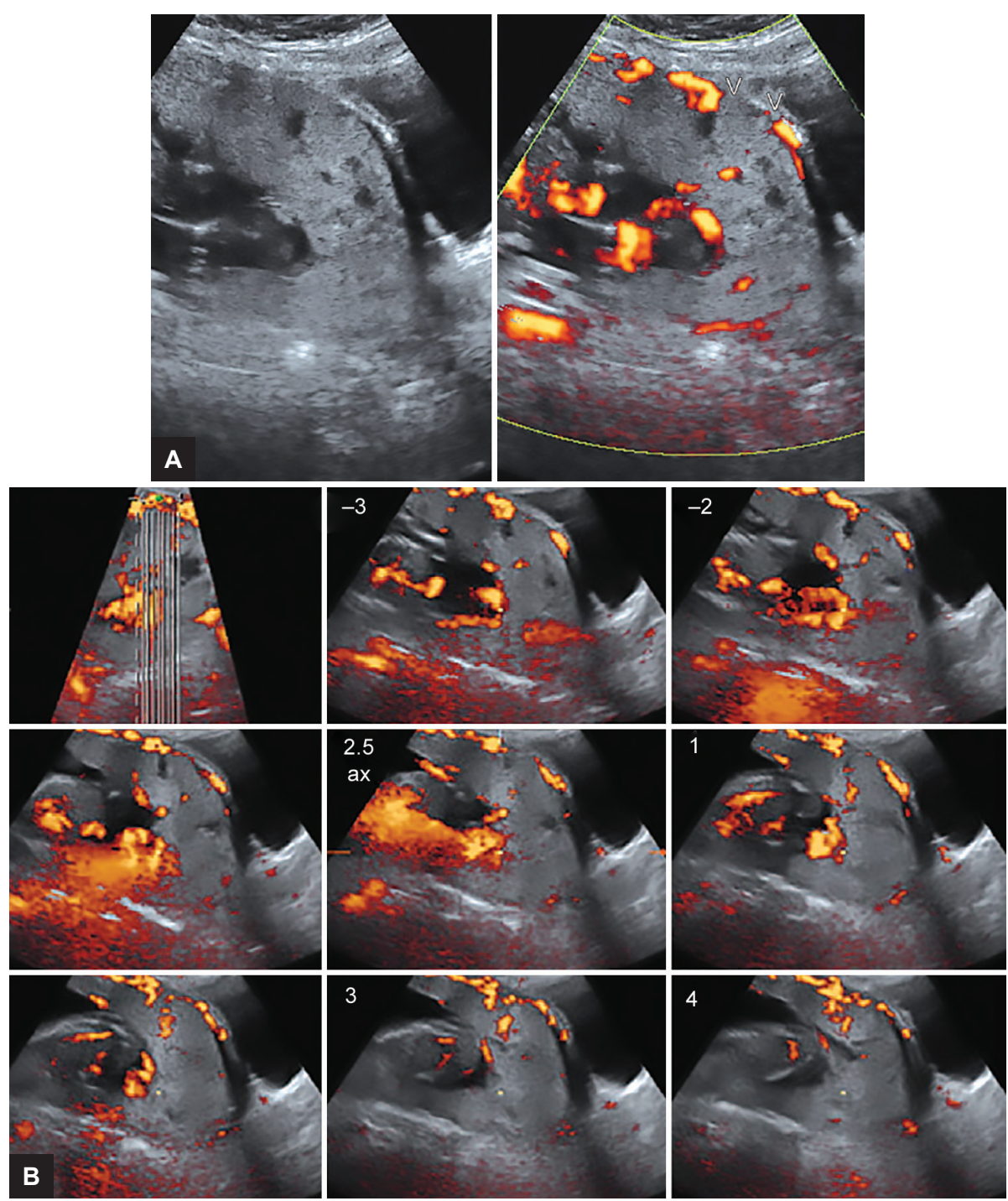

Figs 9A and B: Placenta increta. The 2D and power Doppler studies demonstrate an area of extensive myometrial invasion. The serosal aspect of the uterus is not invaded. The 3D multislice image (tomographic ultrasound imaging) aids in assessing the entire extent of the placenta. This low lying placenta has invaded the posterior uterine wall as well $(++)$
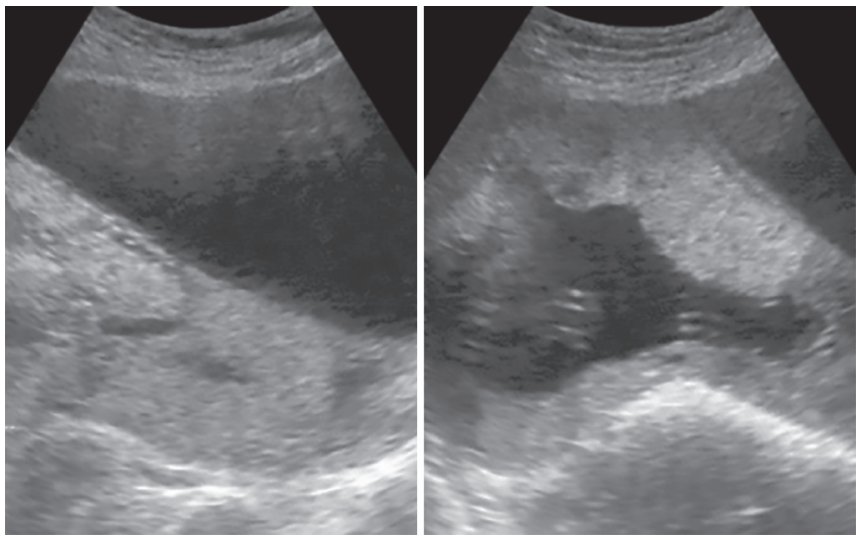

Fig. 10: Low-lying placenta with invasion through the entire myometrium and into the wall of the urinary bladder

can be arranged in advance. Cesarean section is planned at 36 weeks gestation to minimize the risk of spontaneous labor and surgical planning of the site of incision and need for uterine artery balloon occlusion can be individualized. Detailed maternal and family counseling, including issues of future fertility, can be taken into consideration during delivery planning and an option of conservative management may be offered.

With high-risk patients, a targeted transabdominal evaluation of the anterior myometrium and bladder wall is performed using the highest-frequency transducer that can produce an adequate image (with a "full" bladder). Transvaginal ultrasound is always performed when the placenta is low lying.

A multifeature ultrasound evaluation ${ }^{39,44,48}$ enhances the accuracy of detecting the diagnosis, although these are by no means very sensitive. These include loss of the retroplacental clear space, reduced myometrial thickness, placenta previa, placental lacunae, abnormal color Doppler imaging patterns, an irregular urinary bladder wall and abnormal 3D power Doppler vascular mapping. 
The normal retroplacental complex is thinned out ( $2 \mathrm{~mm}$ or less) or obliterated in placenta accreta. The retroplacental complex refers to the hypoechoic space behind the placenta that is normally 10 to $20 \mathrm{~mm}$ thick. A retroplacental hypoechoic line is usually seen with normal placentation. Absence of this hypoechoic line or clear space has been described with placenta accreta. However, absence of the hypoechoic line has also been seen in normal pregnancies and absence of the clear space alone is not predictive for placenta accreta.

Reduced myometrial thickness is tricky to evaluate, overly subjective, difficult to replicate, and reports in literature are scant. This sign has, therefore, never been reliable.

Placenta previa significantly increases the risk for placenta accreta: 6.8 to $10 \%$ among affected women. However, only $88 \%$ of cases of placenta accreta are associated with placenta previa.

Multiple hypoechoic or anechoic lacunae are often evident in the placenta (Fig. 11). These may give it a Swiss-cheese appearance.

Invasion of the bladder or rectum may be evident (Fig. 12).
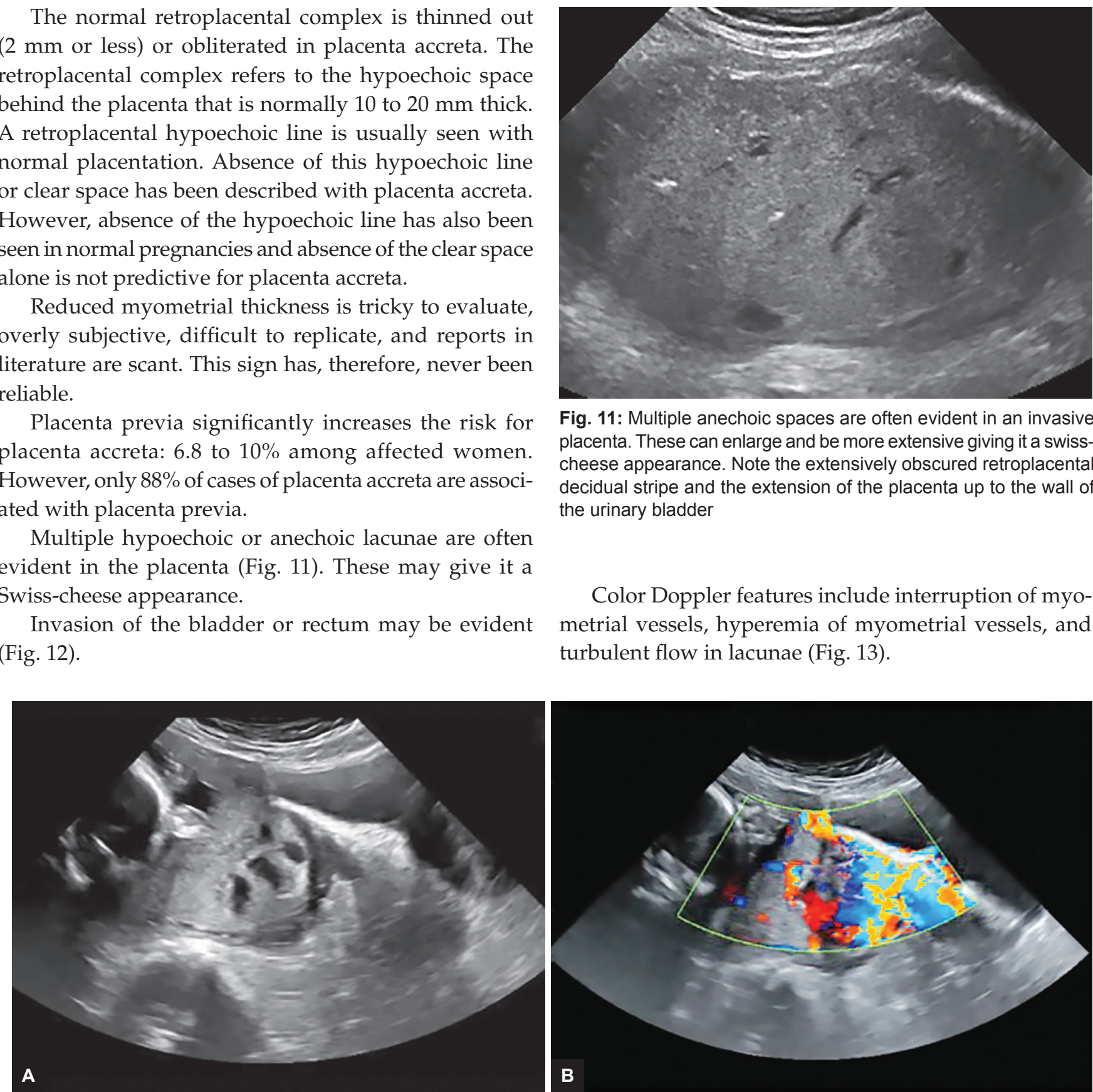

Fig. 11: Multiple anechoic spaces are often evident in an invasive placenta. These can enlarge and be more extensive giving it a swisscheese appearance. Note the extensively obscured retroplacental decidual stripe and the extension of the placenta up to the wall of the urinary bladder

Color Doppler features include interruption of myometrial vessels, hyperemia of myometrial vessels, and turbulent flow in lacunae (Fig. 13).

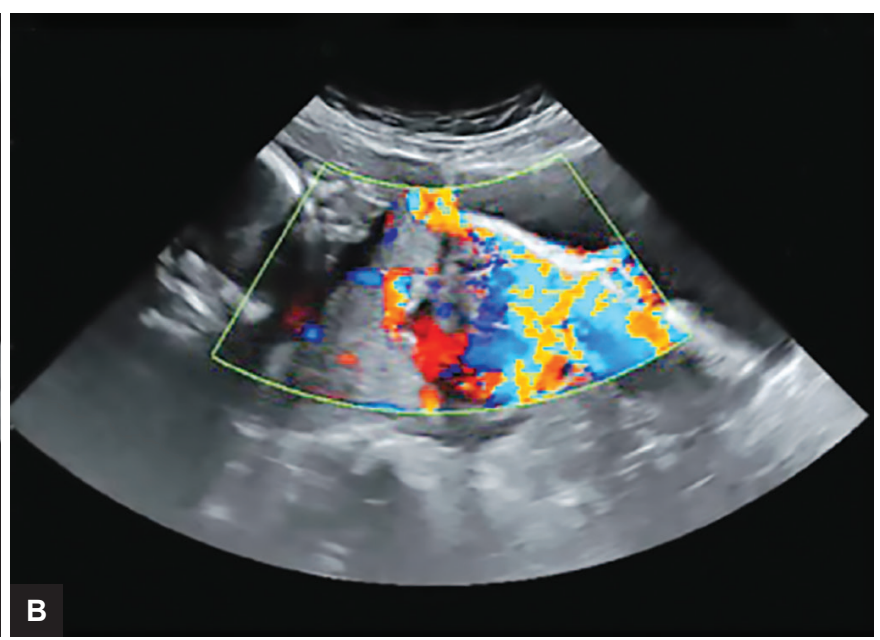

Figs $12 \mathrm{~A}$ and B: Complete placenta previa with a Swiss cheese morphology extending through the myometrium and into the urinary bladder
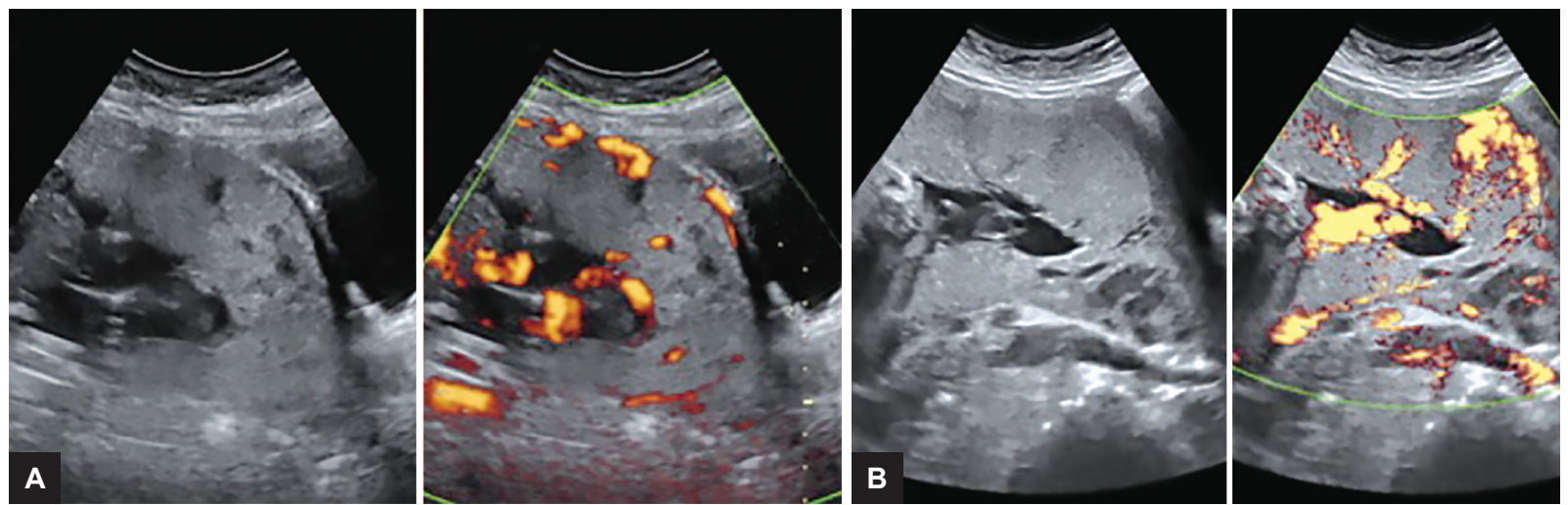

Figs 13A and B: Color Doppler features of placenta accreta include interruption of myometrial vessels, hyperemia of myometrial vessels and turbulent flow in lacunae 

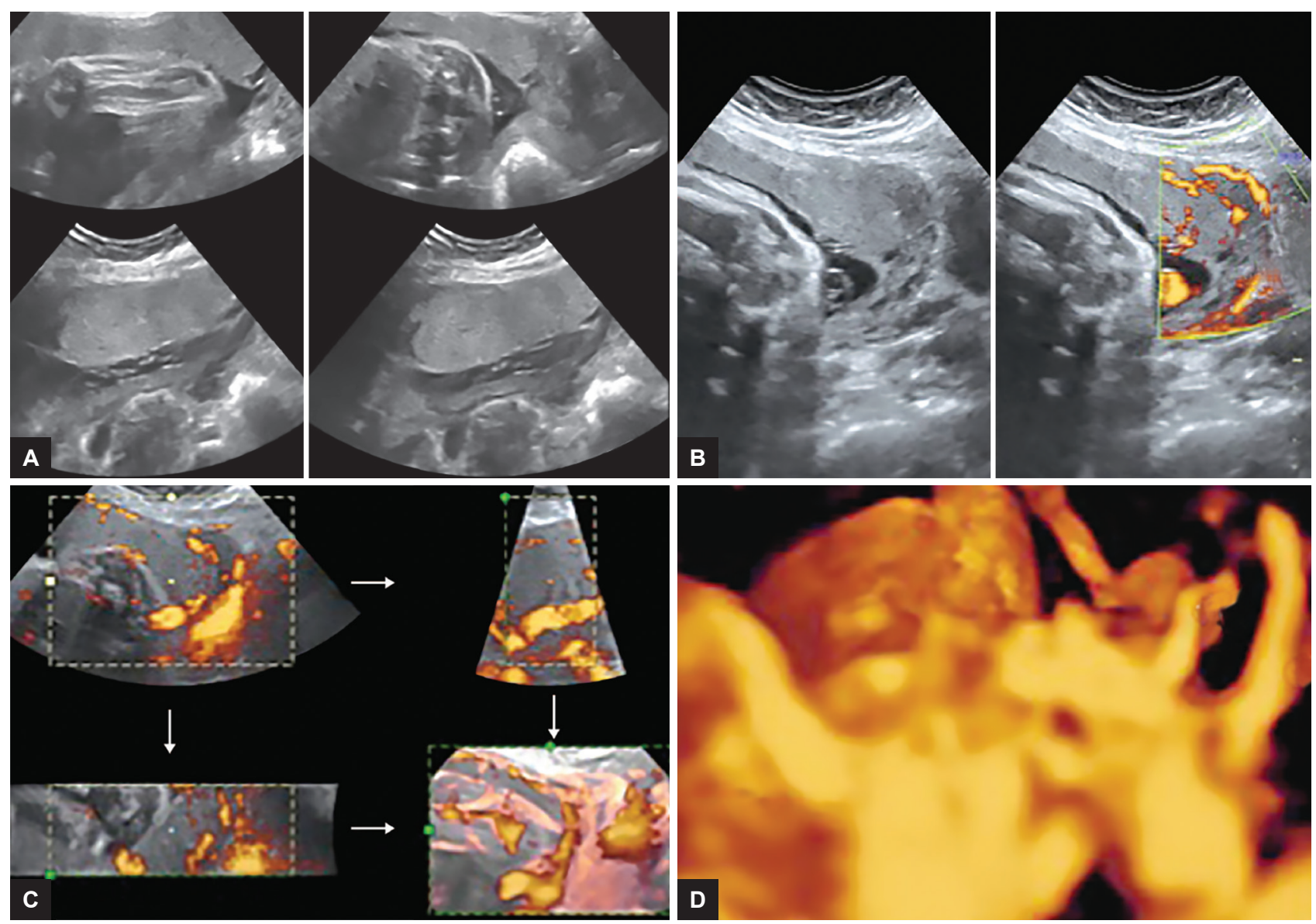

Figs 14A to D: The 3D power Doppler of the placenta. The multislice format confirms multiple areas of invasive placenta. The 3D acquisitions and subsequent rendering formats ensure that the placenta is evaluated throughout its extent. Note the multiple vessels arising radially from the placental vessels in the 3D angio mode rendering $(<)$

The 3D power Doppler studies have helped to identify a new reliable sign.$^{49}$ Normal placentas show vessels that run parallel to the long axis of the uterus. Invasive placentas show branches that run perpendicular to these main vessels and show a course running through the myometrium (Fig. 14).

Recent MRI reports are encouraging. ${ }^{44,50-52}$ The most useful findings are uterine bulging, heterogeneous signal intensity within the placenta, and dark intraplacental bands on T2-weighted images. The MRI protocols are, however, cumbersome and demand a meticulous technique.

\section{CONCLUSION}

Ultrasound is currently the finest tool for assessing the placenta. Recent advances in imaging have reduced the gap between negative ultrasound examinations and critical placental disease.

\section{REFERENCES}

1. Oppenheimer L; Maternal Fetal Medicine Committee. Diagnosis and management of placenta previa. J Obstet Gynaecol Can 2007 Mar;29(3):261-266.

2. McClure N, Dorman JC. Early identification of placenta praevia. Br J Obstet Gynaecol 1990 Oct;97(10):959-961.
3. Edlestone DI. Placental localization by ultrasound. Clin Obstet Gynecol 1977 Jun;20(2):285-287.

4. King DL. Placental ultrasonography. JCU 1973 Mar;1(1):21-26.

5. Timor-Tritsch, IE.; Rottem, S. Transvaginal Sonography. New York: Elsevier; 1987. pp. 1-13.

6. Townsend RR, Laing FC, Nyberg DA, Jeffrey RB, Wing VW. Technical factors responsible for placental migration: sonographic assessment. Radiology 1986 Jul;160(1):105-108.

7. Lauria MR, Smith RS, Treadwell MC, Comstock CH, Kirk JS, Lee W, Bottoms SF. The use of second-trimester transvaginal sonography to predict placenta previa. Ultrasound Obstet Gynecol 1996 Nov;8(5):337-340.

8. Farine D, Fox HE, Timor-Tritsch I. Vaginal ultrasound for ruling out placenta previa. Br J Obstet Gynecol 1989 Jan;96(1): 117-119.

9. Smith RS, Lauria MR, Comstock $\mathrm{CH}$, Treadwell MC, Kirk JS, Lee W, Bottoms SF. Transvaginal ultrasonography for all placentas that appear to be low-lying or over the internal cervical os. Ultrasound Obstet Gynecol 1997 Jan;9(1): 22-24.

10. Farine D, Fox HE, Jakobson S, Timor-Tritsch IE. Vaginal ultrasound for diagnosis of placenta previa. Am J Obstet Gynecol 1988 Sep;159(3):566-569.

11. Oyelese Y. Placenta previa: the evolving role of ultrasound. Ultrasound Obstet Gynecol 2009 Aug;34(2):123-126.

12. Leerentveld RA, Gilberts EC, Arnold MJ, Wladimiroff JW. Accuracy and safety of transvaginal sonographic placental localization. Obstet Gynecol 1990 Nov;76(5 Pt 1):759-762. 
13. Sherman SJ, Carlson DE, Platt LD, Medearis AL. Transvaginal ultrasound: does it help in the diagnosis of placenta previa? Ultrasound Obstet Gynecol 1992 Jul;2(4):256-260.

14. Hill LM, DiNofrio DM, Chenevey P. Transvaginal sonographic evaluation of first-trimester placenta previa. Ultrasound Obstet Gynecol 1995 May;5(5):301-303.

15. Simon EG, Fouche CJ, Perrotin F. Three-dimensional transvaginal sonography in third-trimester evaluation of placenta previa. Ultrasound Obstet Gynecol 2013 Apr;41(4):465-468.

16. Committee on Obstetric Practice. Opinion No. 529 on Placenta accreta. Obstet Gynecol 2012 Jul;120(1):207-211.

17. Webb JA, Thomsen HS, Morcos SK; Members of Contrast Media Safety Committee of European Society of Urogenital Radiology (ESUR). The use of iodinated and gadolinium contrast media during pregnancy and lactation. Eur Radiol 2005 Jun;15(6):1234-1240.

18. Kanal E, Barkovich AJ, Bell C, Borgstede JP, Bradley WG Jr, Froelich JW, Gilk T, Gimbel JR, Gosbee J, Kuhni-Kaminski E, et al; ACR Blue Ribbon Panel on MR Safety. ACR guidance document for safe MR practices: 2007. AJR Am J Roentgenol 2007 Jun;188(6):1447-1474.

19. Finberg, HJ. Umbilical cord and amniotic membranes. In McGahan JP, Goldberg BB, editors. Diagnostic ultrasound-a logical approach. 1st ed. Philadelphia (PA): Lippincott-Raven Publishers; 1998. pp. 201-229.

20. Predanic M, Perni SC, Baergen RN, Jean-Pierre C, Chasen ST, Chervenak FA. A sonographic assessment of different patterns of placenta previa "migration" in the third trimester of pregnancy. J Ultrasound Med 2005 Jun;24(6):773-780.

21. Heller HT, Mullen KM, Gordon RW, Reiss RE, Benson CB. Outcomes of pregnancies with a low-lying placenta diagnosed on second-trimester sonography. J Ultrasound Med 2014 Apr;33(4):691-696.

22. Mustafa SA, Brizot ML, Carvalho MHB, Watanabe L, Kahhale S, Zugaib Z. Transvaginal ultrasonography in predicting placenta previa at delivery: a longitudinal study. Ultrasound Obstet Gynecol 2002 Oct;20(4):356-359.

23. Yang Q, Wen SW, Oppenheimer L, Chen XK, Black D, Gao J, Walker MC. Association of caesarean delivery for first birth with placenta praevia and placental abruption in second pregnancy. BJOG 2007 May;114(5):609-613.

24. Krasznai I, Rigo J Jr, Boze T, Papp Z. Uncommon type of placentation after previous cesarean deliveries. Obstet Gynecol 2003 Sep;102(3):549-551.

25. Kurjak A, Barsic B. Changes of placental site diagnosed by repeated ultrasonic examination. Acta Obstet Gynecol Scand 1977;56(3):161-165.

26. Becker RH, Vonk R, Mende BC, Ragosch V, Entezami M. The relevance of placental location at 20-23 gestational weeks for prediction of placenta previa at delivery: evaluation of 8650 cases. Ultrasound Obstet Gynecol 2001 Jun;17(6):496-501.

27. Taipale P. Hiilesmaa V, Ylostalo P. Transvaginal ultrasonography at 18-23 weeks in predicting placenta previa at delivery. Ultrasound Obstet Gynecol 1998 Dec;12(6):422-425.

28. Oppenheimer L, Holmes P, Simpson N, Dabrowski A. Diagnosis of low-lying placenta: can migration in the third trimester predict outcome? Ultrasound Obstet Gynecol 2001 Aug;18(2):100-102.

29. Ghourab S. Third-trimester transvaginal ultrasonography in placenta previa: does the shape of the lower placental edge predict clinical outcome? Ultrasound Obstet Gynecol 2001 Aug;18(2):103-108.
30. Ghi T, Contro E, Martina T, Piva M, Morandi R, Orsini LF, Meriggiola MC, Pilu G, Morselli-Labate AM, De Aloysio D, et al. Cervical length and risk of antepartum bleeding in women with complete placenta previa. Ultrasound Obstet Gynecol 2009 Feb;33(2):209-212.

31. Sekiguchi A, Nakai A, Okuda N, Inde Y, Takeshita T. Consecutive cervical length measurements as a predictor of preterm cesarean section in complete placenta previa. J Clin Ultrasound 2015 Jan;43(1):17-22.

32. Shin JE, Shin JC, Lee Y, Kim SJ. Serial change in cervical length for the prediction of emergency cesarean section in placenta previa. PLoS One 2016 Feb;11(2):e0149036.

33. Saitoh M, Ishihara K, Sekiya T, Araki T. Anticipation of uterine bleeding in placenta previa based on vaginal sonographic evaluation. Gynecol Obstet Invest 2002;54(1):37-42.

34. Droste S, Keil K. Expectant management of placenta praevia: cost benefit analysis of outpatient treatment. Am J Obstet Gynecol 1994 May;170(5 pt 1):1254-1257.

35. Mouer JR. Placenta praevia: antepartum conservative management, inpatient versus outpatient. Am J Obstet Gynecol 1994 Jun;170(6):1683-1686.

36. Dola CP, Garite TJ, Dowling DD, Friend D, Ahdoot D, Asrat T. Placenta previa: does its type affect pregnancy outcome? Am J Perinatol 2003 Oct;20(7):353-360.

37. Nelson JP. Interventions for suspected placenta praevia. Cochrane Database Syst Rev 2003;2:CD001998.

38. Arias F. Cervical cerclage for the temporary treatment of patients with placenta previa. Obstet Gynecol 1988 Apr;71(4):545-548.

39. Oyelese KO, Smulian JC. Placenta previa, placenta accreta, and vasa previa. Obstet Gynecol 2006 Apr;107(4):927-941.

40. Bhide A, Thilaganathan B. Recent advances in the management of placenta previa. Curr Opin Obstet Gynecol 2004 Dec;16(6):447-451.

41. Finberg HJ, Williams JW. Placenta accreta: prospective sonographic diagnosis in patients with placenta previa and prior cesarean section. J Ultrasound Med 1992 Jul;11(7): 333-343.

42. O'Brien JM, Barton JR, Donaldson ES. The management of placenta percreta: conservative and operative strategies. Am J Obstet Gynecol 1996 Dec;175(6):1632-1638.

43. Ouellet A, Sallout B, Oppenheimer LW. Outcomes of surgical versus conservative management of placenta accreta-percreta: systematic review of literature and case series. Am J Obstet Gynecol 2003 Dec;189(6):S130.

44. Mazouni C, Gorincour G, Juhan V, Bretelle F. Placenta accreta: a review of current advances in prenatal diagnosis. Placenta 2006 Jul;28(7):599-603.

45. Abramowicz JS, Sheiner E. Ultrasound of the placenta: a systematic approach. Part I: imaging. Placenta 2008 Mar;29(3):225-240

46. Wu S, Kocherginsky M, Hibbard JU. Abnormal placentation: twenty-year analysis. Am J Obstet Gynecol 2005 May;192(5):1458-1461.

47. Gielchinsky Y, Rojansky N, Fasouliotis SJ, Ezra Y. Placenta accretae-summary of 10 years: a survey of 310 cases. Placenta 2002 Feb-Mar;23(2-3):210-214.

48. Comstock $\mathrm{CH}$. Antenatal diagnosis of placenta accreta: a review. Ultrasound Obstet Gynecol 2005 Jul;26(1):89-96.

49. Shih JC, Palacios Jaraquemada JM, Su YN, Shyu MK, Lin CH, Lin SY, Lee CN. Role of three-dimensional power Doppler in 
the antenatal diagnosis of placenta accreta: comparison with gray-scale and color Doppler techniques. Ultrasound Obstet Gynecol 2009 Feb;33(2):193-203.

50. Lax A, Prince MR, Mennitt KW, Schwebach JR, Budorick NE. The value of specific MRI features in the evaluation of suspected placental invasion. Magn Reson Imaging 2007 Jan;25(1):87-93.
51. Lim PS, Greenberg M, Edelson MI, Bell KA, Edmonds PR, Mackey AM. Utility of ultrasound and MRI in prenatal diagnosis of placenta accreta: a pilot study. AJR Am J Roentgenol 2011 Dec;197(6):1506-1513.

52. Baughman WC, Corteville JE, Shah RR. Placenta accreta: spectrum of US and MR imaging findings. Radiographics 2008 Nov-Dec;28(7):1905-1916. 